\title{
A corrected version of the Timed-25 Foot Walk Test with a dynamic start to capture the maximum ambulation speed in multiple sclerosis patients
}

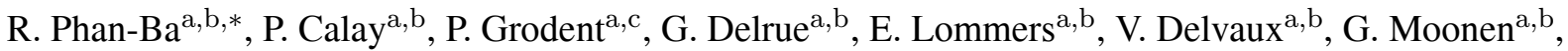 \\ G. Nagels ${ }^{d}$ and S. Belachew ${ }^{a}, b$ \\ ${ }^{a}$ MYelin Disorders REseArch teaM (MYDREAM), Liège, Belgium \\ ${ }^{\mathrm{b}}$ Department of Neurology, C.H.U. of Liège, Liège, Belgium \\ ${ }^{\mathrm{c}}$ Department of Physical Medicine and Rehabilitation, C.H.U. of Liège, Liège, Belgium \\ ${ }^{\mathrm{d}}$ National Center For Multiple Sclerosis, Melsbroek, Belgium
}

\begin{abstract}
Background: No clinical test is currently available and validated to measure the maximum walking speed (WS) of multiple sclerosis (MS) patients. Since the Timed 25-Foot Walk Test (T25FW) is performed with a static start, it takes a significant proportion of the distance for MS patients to reach their maximum pace.

Objectives: In order to capture the maximum WS and to quantify the relative impact of the accelerating phase during the first meters, we compared the classical T25FW with a modified version $\left(\mathrm{T}_{2} 5 \mathrm{FW}^{+}\right)$allowing a dynamic start after a 3 meters run-up.

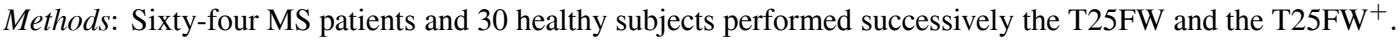

Results: The $\mathrm{T}_{2} 5 \mathrm{FW}^{+}$was performed faster than the T25FW for the vast majority of MS and healthy subjects. In the MS population, the mean relative gain of speed due to the dynamic start on $\mathrm{T}_{2} 5 \mathrm{FW}^{+}$was independent from the EDSS and from the level of ambulation impairment. Compared to healthy subjects, the relative difference between dynamic versus static start was more important in the MS population even in patients devoid of apparent gait impairment according to the T25FW.

Conclusion: The $\mathrm{T}_{2} 5 \mathrm{FW}^{+}$allows a more accurate measurement of the maximum WS of MS patients, which is a prerequisite to reliably evaluate deceleration over longer distance tests. Indirect arguments suggest that the time to reach the maximum WS may be partially influenced by the cognitive impairment status. The maximum WS and the capacity of MS patients to accelerate on a specific distance may be independently regulated and assessed separately in clinical trials and rehabilitation programs.
\end{abstract}

Keywords: Multiple sclerosis, gait, outcome measurement, maximum walking speed, acceleration, disability progression

\section{Introduction}

Ambulation impairment is one of the most prominent and frequent clinical feature of multiple sclerosis (MS) [1] with major consequences on patient's auton-

${ }^{*}$ Corresponding author: Rémy Phan-Ba, MD, Department of Neurology, C.H.U. of Liège, 1, Avenue de l'Hôpital, 4000, Liège, Belgium. Tel.: +32 436672 55; Fax: +32 436674 99; E-mail: remy. phanba@chu.ulg.ac.be. omy. Gait disturbances have a high impact on the personal, professional and social burden of this disease [2, 3]. The onset of permanent gait limitations is often conceived as a late process in the course of the disease, and ambulation is only taken into account beyond the score of 4.0 on the Expanded Disability Status Scale (EDSS) [4]. However, several studies have suggested that the restriction of ambulation performances might occur much earlier than previously considered [5-7]. Furthermore, the precise monitoring of walking capac- 
ities in MS patients is gaining more and more attention, since emerging rehabilitation techniques [8], symptomatic [9] and disease modifying [10] therapies are becoming increasingly effective with a substantial proportion of patients experiencing some degree of clinical improvement in specific conditions.

Although several alternative approaches have been developped [11-14], the Timed 25-Foot Walk Test [15, 16] $(\mathrm{T} 25 \mathrm{FW})$ is currently the most widely used test to evaluate locomotion in clinical trials. Although highly relevant to the characterization of patients' daily functional impairment, scarce data are available in regard of the precise gait-related physiological correlates of the T25FW. In fact, we recently demonstrated that the T25FW does not effectively measure the real maximum walking speed, since the mean walking speed (WS) is paradoxically higher on a longer distance (i.e. 100 meters) test [14].

Several hypotheses were proposed to explain this apparent discrepancy, such as a more important influence of the precision of the examining technician and of motivational issues in a short distance walk test. We also speculated that the relative duration and length of the accelerating phase during the very first meters of the test could contribute to the slower WS observed on a short distance walking test.

In order to investigate the potential weight of these first meters of acceleration in the T25FW performances, we proposed a corrected version of the test where a dynamic start is allowed 3 meters before the starting line (i.e. $\mathrm{T}_{25 \mathrm{FW}^{+}}$). We assumed that 3 meters, which represent nearly $40 \%$ of the full 25 -foot distance was likely enough to reach a maximum walking pace for most MS patients. Hence, this paradigm allows to exclude or severely reduce the relative impact of the "acceleration phase" in the test and to compare the observed mean walking speed on the same distance with that of the conventional T25FW (i.e. with a static start right behind the line). To our knowledge no head-to-head comparison between static and dynamic starting protocols has ever been performed among the various methodologies previously used to assess the WS in MS $[18,19]$.

\section{Methods}

Sixty-four patients with a diagnosis of relapsingremitting or progressive MS according to the McDonald [20] criteria and 30 age and sex matched healthy controls used as a control group were enrolled in the study. We selected MS patients with a broad range of walking performances with an EDSS $\leqslant 6.5$.

The study protocol was approved by the local ethics committee from the medical faculty of Liège.

The T25FW was performed according to the published standardized instructions $[15,16]$.

The $\mathrm{T}_{25 \mathrm{FW}^{+}}$was also strictly following the guidelines of the T25FW $[15,16]$, except that the subjects were allowed to take a 3 meters run-up before the starting line. This run-up was clearly demarcated on the ground. The raters were instructed for both tests to start the stopwatch as soon as the lead foot crossed the starting line of the 25-foot distance, and to stop it when the lead foot crossed the finish line.

The raters had been trained and certified for the administration of all the tests from the Multiple Sclerosis Functionnal Composite score (RP, PC or SB). EDSS scores were collected by certified EDSS-raters (RP or $\mathrm{SB})$.

The $\mathrm{T} 25 \mathrm{FW}$ and the $\mathrm{T} 25 \mathrm{FW}^{+}$were performed as the first part of a multi-test evaluation during routine clinical evaluations, in an outpatient neurological MS department, between November 2009 and October 2010. The T25FW was first performed twice as well as the $\mathrm{T}_{25} 5 \mathrm{FW}^{+}$after 5 minutes of break in between. For both tests, the results were expressed as the mean time of the 2 trials.

The Mean WS expressed in meters per second for both tests were obviously calculated by dividing $7.62 \mathrm{~m}$ (i.e. 25 feet) by the time to perform the T25FW or the

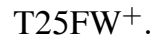

Non parametric unpaired t-test was used for between group comparisons, while non parametric paired t-test was used for within group comparisons. Pearson's correlation coefficient was used to assess the relationship between the two tests. All statistical tests were applied with a two-tailed analysis and 0.05 as a level of significance, and were performed using GraphPad Prism, version 4.0b for Macintosh, GraphPad Software, San Diego California USA (www.graphpad.com).

\section{Results}

The baseline characteristics of MS patients $(n=64)$ and healthy control volunteers $(n=30)$ are summarized in Table 1. No major differences were observed between the two populations. In the MS population, the median EDSS was 3.0 (ranging from 0 to 6.5). The distribution of the population throughout the different EDSS subgroups was harmonious. 
Table 1

Characteristics of MS patients and control subjects

\begin{tabular}{lcc}
\hline & MS patients & Healthy controls \\
\hline Number of patients/controls & 64 & 30 \\
Gender (\% female) & 59 & 71 \\
Age (median, range, years) & $39,15-64$ & $25,18-60$ \\
Body Mass Index (mean $\left.\pm \mathrm{SD}, \mathrm{kg} / \mathrm{m}^{2}\right)$ & $23,55 \pm 4,2$ & $25,18 \pm 9,6$ \\
EDSS (median, range) & $3.0,0-6.5$ & n.a. \\
EDSS 0-2.0 (number of patients, \%) & $25(39)$ & n.a. \\
EDSS 2.5-4.0 (number of patients, \%) & $24(37,5)$ & n.a. \\
EDSS 4.5-6.5 (number of patients, \%) & $15(23,4)$ & n.a. \\
MS type (CIS/RR/SP/PP, $\%)^{1}$ & $9,4 / 65,6 / 12,5 / 12,5$ & n.a. \\
Disease duration (mean \pm SD, range, years) & $10,4 \pm 9,3,0-35$ & n.a. \\
\hline
\end{tabular}

1: CIS, Clinically Isolated Syndrome; RR, Relapsing-Remitting; SP, Secondary Progressive; PP, Primary Progressive.

A
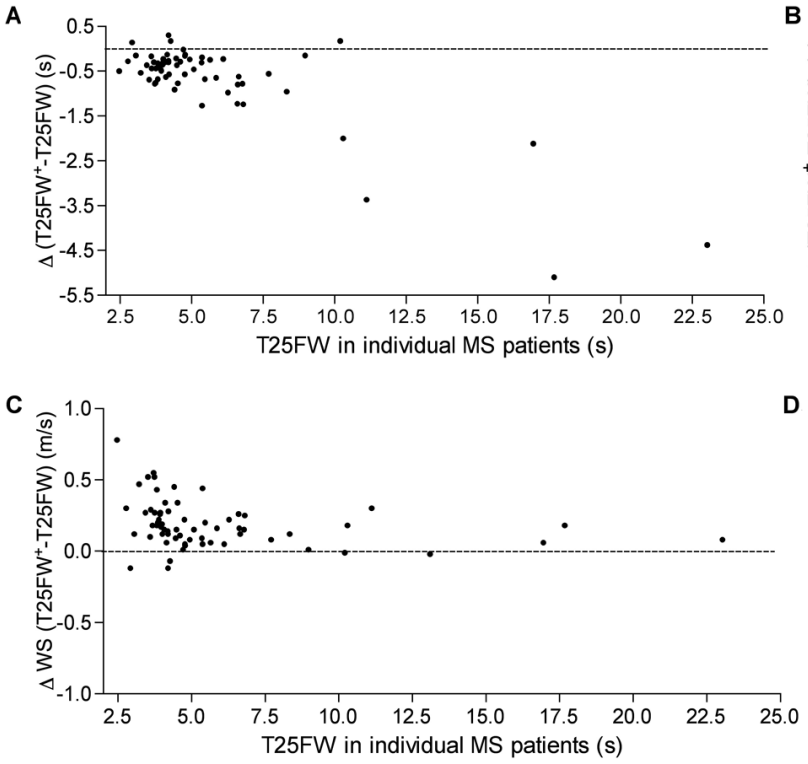
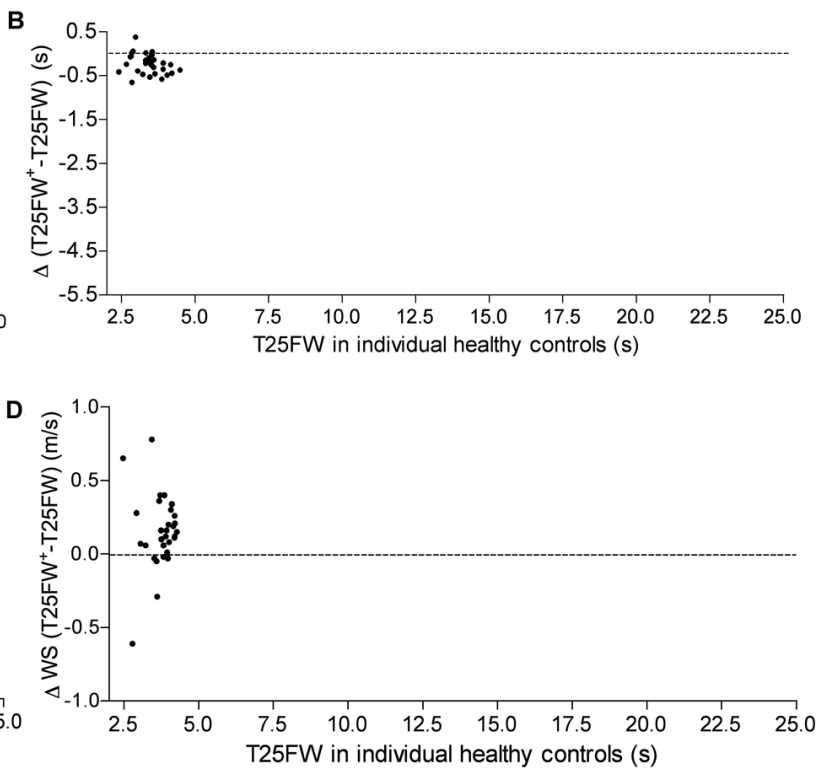

Fig. 1. Absolute difference between the $\mathrm{T} 25 \mathrm{FW}^{+}$and the $\mathrm{T} 25 \mathrm{FW}\left(\Delta \mathrm{T} 25 \mathrm{FW}^{+}-\mathrm{T} 25 \mathrm{FW}\right)$ in individual MS patients (A) and healthy controls $(\mathrm{B})$. Absolute difference between the mean calculated walking speed (WS) in both tests $\left(\Delta \mathrm{WS}\left(\mathrm{T}_{25} 5 \mathrm{FW}^{+}-\mathrm{T} 25 \mathrm{FW}\right)\right)$ in $\mathrm{MS}$ patients $(\mathrm{C})$ and healthy controls (D). All results were classified by increasing T25FW.

In both healthy control volunteers and MS patients, the two tests displayed a good correlation (Pearson's correlation coefficient $=0.8554$ and 0.9791 , both $p<$ 0.0001 , respectively).

As highlighted by individual absolute differences in time (Figs 1A and 1B) and in mean WS (Figs 1C and 1D), the vast majority of MS patients $(92 \%, 59 / 64$, Figs $1 \mathrm{~A}$ and $1 \mathrm{C})$ and healthy control volunteers (80\%, 24/30, Figs 1B and 1D) performed consistently faster on the $\mathrm{T}_{2} 5 \mathrm{FW}^{+}$than on the $\mathrm{T} 25 \mathrm{FW}$ with varying levels of differences between the two tests (Fig. 1).

The difference between the two tests was further confirmed by a mean WS that was significantly higher for

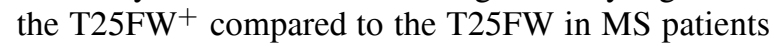
$(1.80 \pm 0.65$ vs $1.62 \pm 0.57$, respectively, mean $\pm S D$, $\mathrm{m} / \mathrm{s}, p<0.0001)$ and healthy controls $(2.46 \pm 0.43 \mathrm{vs}$ $2.31 \pm 0.37$, respectively, mean $\pm \mathrm{SD}, \mathrm{m} / \mathrm{s}, p<0.0001)$ (Fig. 2A). Ambulation speed performances were also significantly slower for MS patients compared to that of healthy control volunteers in both tests $(p<0.0001$ for both tests). The $\mathrm{T}_{2} 5 \mathrm{FW}^{+}$was performed consistently faster than the T25FW in all subgroups of MS patients stratified according to their EDSS status (0 to 2.0, 2.5 to 4.0 , and 4.5 to 6.5 ; all $p<0.0001$, Fig. $2 \mathrm{~B}$ ). In order to dichotomize MS patients according to their normal versus abnormal walking performances, we fixed a threshold value of 4,43 seconds, corresponding to the mean T25FW of healthy controls plus twice the standard deviation. We then arbitrarily separated the MS population between the so-called "normal walker" group with 
A

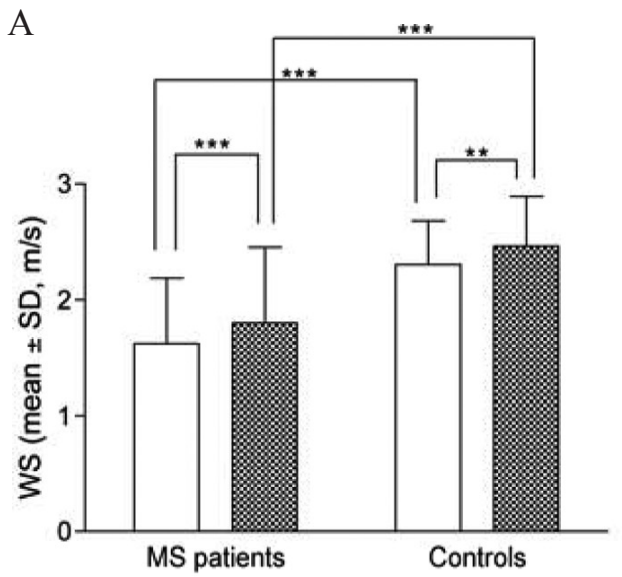

B

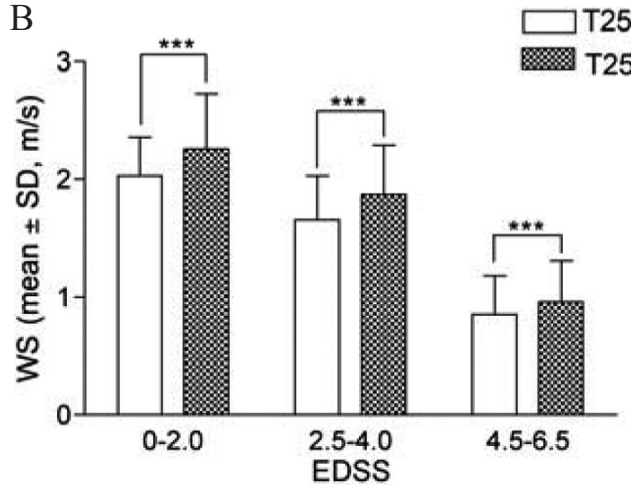

C

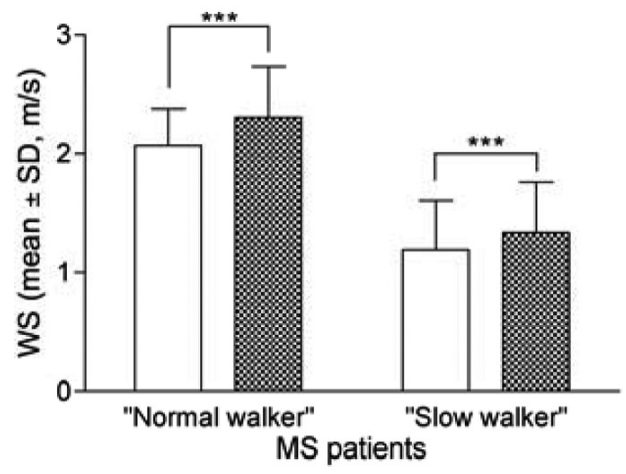

Fig. 2. Histograms depicting the mean walking speed (WS) on the $\mathrm{T}_{2} 5 \mathrm{FW}^{+}$and $\mathrm{T} 25 \mathrm{FW}$ in the global MS patient population and healthy controls (A), across different levels of disability status evaluated through the EDSS (B), and in "normal" versus "slow" walking MS patients (C).

a T25FW $\leqslant 4.43 \mathrm{~s}$ ( $n=31,48 \%$ of the population) and the "slow walker" group with a T25FW $>4.43 \mathrm{~s}$ ( $n=$ $33,52 \%$ of the population). The mean WS was also significantly faster in the $\mathrm{T} 25 \mathrm{FW}^{+}$both for the "normal" and "slow" walker MS groups ( $p<0.0001$, Fig. 2 C).
We calculated the individual relative differences between WS in the two tests: i.e. the difference between WS on $\mathrm{T}_{2} 5 \mathrm{FW}^{+}$minus WS on T25FW, divided by WS on $\mathrm{T} 25 \mathrm{FW}^{+}$. The mean relative difference between

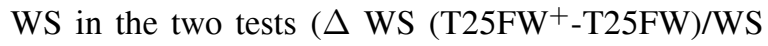
$\mathrm{T}^{25 \mathrm{FW}^{+}}$) was significantly higher in MS patients compared to controls $(10.2 \pm 7.7 \%$, versus $5.7 \pm 9.1 \%$, mean $\pm \mathrm{SD} ; p=0.0148$, Fig. 3A). No significant difference was found in the mean relative difference between WS in the two tests for the subgroups of MS patients at different levels of disability assessed by their EDSS status (Fig. 3A). The mean relative difference between WS in the two tests was also significantly higher in "normal" $(10.0 \pm 7.2 \%$, mean $\pm \mathrm{SD}, p=0.0461)$ and "slow" $(10.4 \pm 8.2 \%$, mean $\pm \mathrm{SD}, p=0.0363)$ walker MS patients compared with that of healthy control volunteers (5.7 $\pm 9.1 \%$, mean \pm SD) (Fig. 3B). No significant difference was found in this regard between "normal" and "slow" walker MS patients (Fig. 3B).

\section{Discussion}

The present study show that the time to reach the maximum WS has a significant impact in the results of the conventional T25FW, since a run-up of 3 meters can lead to a significantly higher mean WS measured on the same 25 foot distance, both in healthy control volunteers and in all subsets of MS patients. Removing part if not all of this accelerating phase to reach the maximum pace using a 3 meters run-up before the T25FW induced a more important difference between the two tests in MS patients compared to healthy volunteers, regardless of their EDSS status or their ambulation impairment.

The difference between the two tests was also significantly less pronounced in healthy volunteers than in "normal walker" MS subjects with no apparent ambulatory deficit. This observation may reflect the need for a longer distance of accelerating phase to reach the same maximum pace in MS patients, consequently performing a shorter proportion of the classical T25FW at their real maximum WS. This indicates that the maximum WS per se and the capacity of patients to accelerate on a specific distance are two distinct outcome measures, which can be differently affected by symptoms of MS. In comparison with the maximum WS, the acceleration capacity is likely to depend more on the motor reaction time to a simple command, which could be altered in case of mild cognitive dysfunction in MS patients. 

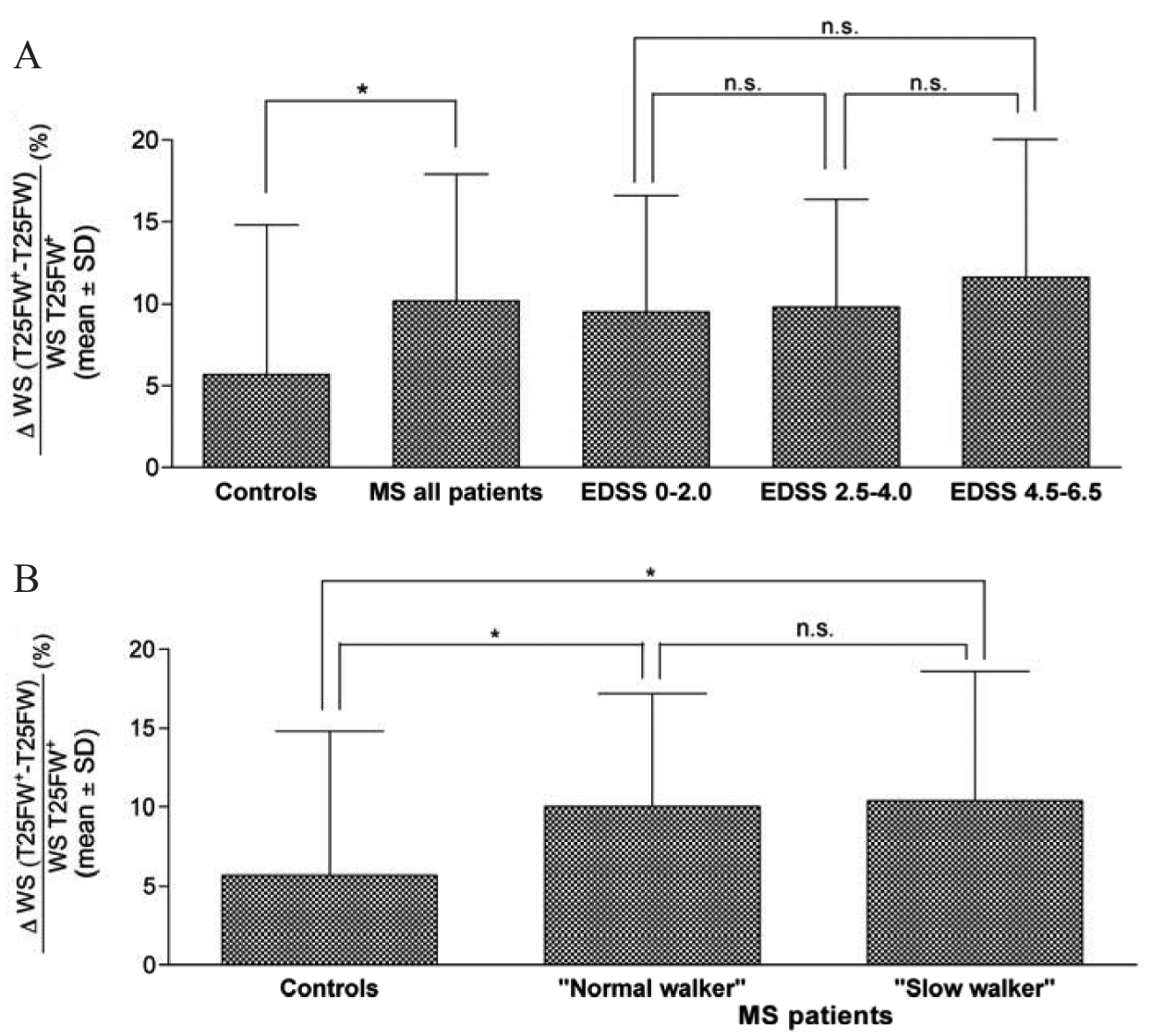

Fig. 3. Histograms depicting the mean relative difference between $\mathrm{WS}$ on the $25 \mathrm{FW}^{+}$and $\mathrm{T} 25 \mathrm{FW}\left(\Delta \mathrm{WS}\left(\mathrm{T}_{2} 5 \mathrm{FW}^{+}-\mathrm{T} 25 \mathrm{FW}\right) / \mathrm{T}^{25} \mathrm{FW}^{+}\right)$ in healthy controls, the global MS patients population (A), across different levels of disability status evaluated through the EDSS (A), and in "normal" versus "slow" walking MS patients (B).

Several studies have demonstrated that true walking impairment or even simple postural control abnormalities can be seen in the early course of MS [5-7,21] as well as in patients where the level of disability remained low or unapparent, with no clinically detectable signs of CNS lesions according to the Kurtzke functional system scores. Hence, beyond the typical pyramidal, proprioceptive, and cerebellar MS symptoms affecting ambulation, other factors that remains to be elucidated probably contribute to walking impairment in this disease. In this regard, the potential link between early cognitive impairment and gait disability should be further investigated [22]. In particular, the present data strengthen the hypothesis that the attention network and information processing speed systems, which are frequently altered early in MS [23,24] may contribute to gait and postural disturbances $[5,22]$ at any stage of the disease course.

For clinical trials particularly when addressing progressive forms of MS, as well as for the field of neu- rorehabilitation, these results emphasize that the classical T25FW needs to be revisited with a propelled start

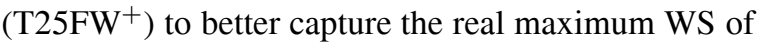
MS patients on short distances. Then only, should the $\mathrm{T}_{25} 5 \mathrm{FW}^{+}$performances be compared to WS measurements performed using longer distance tests such as the Timed 100-Meters Walk Test [14]. This will allow the development of new insightful outcome measures through the calculation of ratios between WS measured on short and longer distances. We think such deceleration indexes may be reliable indicators of ambulation fatigue [25], which is present even at early stages of disease progression [26].

This refinement and improvement of ambulation outcome measures is a necessary step to increase their sensitivity and specificity in order to disentangle the effects of rehabilitation programs, disease-modifying and symptomatic treatments even at low levels of ambulation impairment, which is major component of patients' disability in multiple sclerosis. 


\section{References}

[1] Hobart JC, Riazi A, Lamping DL, Fitzpatrick R, Thompson AJ, Measuring the impact of MS on walking ability: the 12Item MS Walking Scale (MSWS-12), Neurology 60 (2003), 31-6.

[2] Heesen C, Bohm J, Reich C, Kasper J, Goebel M, Gold SM, Patient perception of bodily functions in multiple sclerosis: gait and visual function are the most valuable, Mult Scler 14 (2008), 988-91.

[3] Sutliff MH, Contribution of impaired mobility to patient burden in multiple sclerosis, Curr Med Res Opin (2009),

[4] Kurtzke JF, Rating neurologic impairment in multiple sclerosis: an expanded disability status scale (EDSS), Neurology 33 (1983), 1444-52.

[5] Kalron A, Dvir Z, Achiron A, Walking while talkingdifficulties incurred during the initial stages of multiple sclerosis disease process, Gait Posture 32 (2010), 332-5.

[6] Martin CL, Phillips BA, Kilpatrick TJ, Butzkueven H, Tubridy N, McDonald E, Galea MP, Gait and balance impairment in early multiple sclerosis in the absence of clinical disability, Mult Scler 12 (2006), 620-8.

[7] Corradini ML, Fioretti S, Leo T, Piperno R, Early recognition of postural disorders in multiple sclerosis through movement analysis: a modeling study, IEEE Trans Biomed Eng 44 (1997), 1029-38.

[8] Sacco R, Bussman R, Oesch P, Kesselring J, Beer S, Assessment of gait parameters and fatigue in MS patients during inpatient rehabilitation: a pilot trial, J Neurol 258(5) (May 2011), 889-94. Epub 2010 Nov 15.

[9] Goodman AD, Brown TR, Edwards KR, Krupp LB, Schapiro RT, Cohen R, Marinucci LN, Blight AR, A phase 3 trial of extended release oral dalfampridine in multiple sclerosis, Ann Neurol 68 (2010), 494-502.

[10] Belachew S, Phan-Ba R, Bartholomé E, Delvaux V, Hansen I, Calay P, Hafsi KE, Moonen G, Tshibanda L, Vokaer M, Natalizumab induces a rapid improvement of disability status and ambulation after failure of previous therapy in relapsingremitting multiple sclerosis, Eur J Neurol 18(2) (Feb 2011), 240-5. doi: 10.1111/j.1468-1331.2010.03112.x.

[11] Creange A, Serre I, Levasseur M, Audry D, Nineb A, Boerio D, Moreau T, Maison P, Walking capacities in multiple sclerosis measured by global positioning system odometer, Mult Scler 13 (2007), 220-3.

[12] Gijbels D, Alders G, Van Hoof E, Charlier C, Roelants M, Broekmans T, Op 't Eijnde B, Feys P, Predicting habitual walking performance in multiple sclerosis: relevance of capacity and self-report measures, Mult Scler 16 (2010), 618-26.

[13] Givon U, Zeilig G, Achiron A, Gait analysis in multiple sclerosis: characterization of temporal-spatial parameters using GAITRite functional ambulation system, Gait Posture 29 (2009), 138-42.

[14] Phan-Ba R, Pace A, Calay P, Grodent P, Douchamps F, Hyde R, Hotermans C, Delvaux V, Hansen I, Moonen G, Belachew $\mathrm{S}$, Comparison of the timed 25-foot and the 100-meter walk as performance measures in multiple sclerosis, Neurorehabil Neural Repair 25 (2011), 672-9.

[15] Cutter GR, Baier ML, Rudick RA, Cookfair DL, Fischer JS, Petkau J, Syndulko K, Weinshenker BG, Antel JP, Confavreux C, Ellison GW, Lublin F, Miller AE, Rao SM, Reingold S, Thompson A, Willoughby E, Development of a multiple sclerosis functional composite as a clinical trial outcome measure, Brain 122 (Pt 5) (1999), 871-82.

[16] Fischer JS, Rudick RA, Cutter GR, Reingold SC, The Multiple Sclerosis Functional Composite Measure (MSFC): an integrated approach to MS clinical outcome assessment. National MS Society Clinical Outcomes Assessment Task Force, Mult Scler 5 (1999), 244-50.

[17] Phan-Ba R, Pace A, Calay P, Grodent P, Douchamps F, Hyde R, Hotermans C, Delvaux V, Hansen I, Moonen G, Belachew S, Comparison of the Timed 25-Foot and the 100-Meter Walk as Performance Measures in Multiple Sclerosis, Neurorehabil Neural Repair (2011).

[18] Graham JE, Ostir GV, Fisher SR, Ottenbacher KJ, Assessing walking speed in clinical research: a systematic review, J Eval Clin Pract 14 (2008), 552-62.

[19] Graham JE, Ostir GV, Kuo YF, Fisher SR, Ottenbacher KJ, Relationship between test methodology and mean velocity in timed walk tests: a review, Arch Phys Med Rehabil 89 (2008), 865-72.

[20] Polman CH, Reingold SC, Banwell B, Clanet M, Cohen JA, Filippi M, Fujihara K, Havrdova E, Hutchinson M, Kappos L, Lublin FD, Montalban X, O'Connor P, Sandberg-Wollheim M, Thompson AJ, Waubant E, Weinshenker B, Wolinsky JS, Diagnostic criteria for multiple sclerosis: 2010 revisions to the McDonald criteria, Ann Neurol 69 (2011), 292-302.

[21] Benedetti MG, Piperno R, Simoncini L, Bonato P, Tonini A, Giannini S, Gait abnormalities in minimally impaired multiple sclerosis patients, Mult Scler 5 (1999), 363-8.

[22] Hamilton F, Rochester L, Paul L, Rafferty D, O'Leary CP, Evans JJ, Walking and talking: an investigation of cognitivemotor dual tasking in multiple sclerosis, Mult Scler 15(10) (Oct 2009), 1215-27. Epub 2009 Aug 10.

[23] Schulz D, Kopp B, Kunkel A, Faiss JH, Cognition in the early stage of multiple sclerosis, J Neurol 253 (2006), 1002-10.

[24] Potagas C, Giogkaraki E, Koutsis G, Mandellos D, Tsirempolou E, Sfagos C, Vassilopoulos D, Cognitive impairment in different MS subtypes and clinically isolated syndromes, $J$ Neurol Sci 267 (2008), 100-6.

[25] Phan-Ba R, Calay P, Grodent P, Delrue G, Nagels G, Belachew $\mathrm{S}$. Walking endurance assessment by a deceleration index calculated from performances on short and long distance walking tests in multiple sclerosis. American Academy of Neurology 63rd Annual Meeting. Hawaï Convention Center, Honolulu, Hawaï 2011.

[26] Schwid SR, Thornton CA, Pandya S, Manzur KL, Sanjak M, Petrie MD, McDermott MP, Goodman AD, Quantitative assessment of motor fatigue and strength in MS, Neurology $\mathbf{5 3}$ (1999), 743-50. 